

\title{
APERTEM OS CINTOS: OS DESAFIOS DA COMPETITIVIDADE INTERNACIONAL BRASILEIRA
}

\author{
NOS RANKINGS INTERNACIONAIS, O BRASIL SE DESTACA EM QUESITOS \\ COMO POPULAÇÃO, PIB E TAMANHO DO MERCADO DOMÉSTICO. NO \\ ENTANTO, DEIXA A DESEJAR QUANDO SE TRATA DA CARGA DE IMPOSTOS, \\ CONFIANÇA DA POPULAÇÃO NOS POLÍTICOS E EDUCAÇÃO. SERÁ QUE \\ DECOLAMOS OU ESTAMOS CAINDO?
}

| POR FÁBIO MARIOTTO + PEDRO ZANNI

\section{CRESCIMENTO OU QUEDA?}

Há, tanto no Brasil quanto no exterior, uma sensação de que nosso país perdeu muito do vigor que exibia anos atrás. Depois de publicar uma capa com a figura do Cristo Redentor decolando como um foguete, com a legenda Brazil takes off ("O Brasil decola"), em novembro de 2009, a revista britânica The Economist divulgou recentemente outra capa, desta vez com o Cristo cambaleando no ar e começando a cair, sob o título Has Brazil blown it? (“O Brasil estragou tudo?").

O país também perdeu posição entre os chamados mercados emergentes. Jim O'Neill, influente executivo da Goldman Sachs, que em 2001 cunhou o termo BRIC (Brasil, Rússia, Índia e China) para designar as nações em desenvolvimento que se destacavam no cenário mundial daquela época, recentemente afirmou que três dessas nações o decepcionaram (Brasil, Rússia e Índia). Outros mercados têm chamado sua atenção, principalmente africanos como Nigéria, Tanzânia, Gana e Angola.

As duas avaliações revelam uma reversão de expectativas. Há cerca de dez anos, o Brasil parecia promissor do ponto de vista econômico: suas exportações cresciam, o PIB evoluía satisfatoriamente, os investimentos estrangeiros diretos aumentavam. Recentemente, o quadro se alterou. Muitos observadores expressam essa mudança como uma perda de competitividade internacional, que é a capacidade de um país produzir bens e serviços que tenham participação crescente nos mercados estrangeiros e se promover como um ambiente de negócios favorável a investimentos provindos do exterior.

\section{SOMOS COMPETITIVOS LÁ FORA?}

A competitividade internacional de uma nação pode ser medida de duas formas: por seus efeitos (participação de seus produtos no mercado mundial, produtividade, influxo de investimento estrangeiro direto, etc.) ou pelos fatores que contribuem para que ela exista. Na primeira forma, tem-se uma avaliação geral da pujança econômica do país e da capacidade de produção de seus recursos. A segunda, porém, é mais útil, porque permite identificar seus pontos fortes e fracos e aponta ações que o governo, os setores produtivos e os cidadãos podem empreender para potencializá-la.

O Fórum Econômico Mundial (FEM) publica anualmente os resultados de um levantamento sobre a competitividade 
internacional de cerca de 150 países. Para cada um é calculado o valor de um Índice de Competitividade Global. Na versão de 2013-2014, o Brasil ficou no $56^{\circ}$ lugar entre 148 nações. Entre os BRICs, saiu-se melhor do que a Índia $\left(60^{\circ}\right)$ e a Rússia $\left(64^{\circ}\right)$, mas muito atrás da China $\left(29^{\circ}\right)$, e caiu 8 posições em relação ao ano anterior. A Suíça foi a mais bem colocada no ranking.

Esse índice leva em consideração mais de cem fatores que influenciam a competitividade de um país. As medidas podem ser objetivas (como o PIB) ou subjetivas (como a flexibilidade na fixação de salários). A classificação, primeiramente, é feita por setor, e depois para obter o valor final do índice. Por exemplo: no item "população", o Brasil está em $5^{\circ}$ lugar, o que indica um mercado grande e potencialmente atraente a investimentos produtivos.

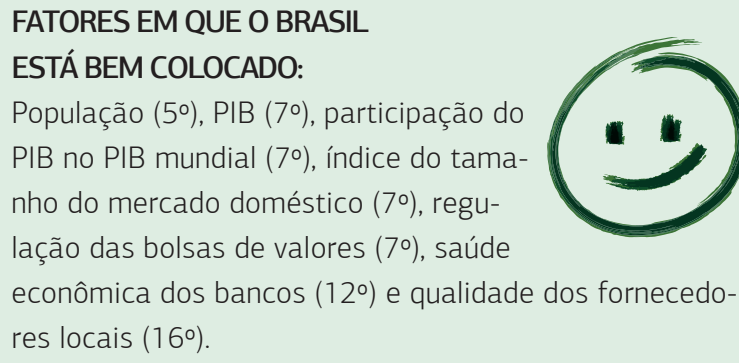

\section{FATORES EM QUE O BRASIL} ESTÁ MAL COLOCADO:

Importações como percentual do PIB

(148 - última posição), peso da regula-

ção governamental (1470), exportações

como percentual do PIB (145), tempo necessário para iniciar um negócio (144\%), efeito dos impostos nos incentivos para investir (140\%), carga total de impostos (140\%), peso dos procedimentos alfandegários (139), efeito dos impostos nos incentivos para trabalhar (138), confiança do público nos políticos (136\%), qualidade da educação em matemática e ciência (136 - atrás de Serra Leoa).

\section{AS EMPRESAS TÊM O PODER}

Para corrigir as deficiências identificadas acima, fica claro que o papel do governo e das empresas é fundamental. Como alerta Michael Porter, professor de Harvard_que estuda o tema, quem compete nos mercados estrangeiros não é o país em si, mas suas organizações. Nota-se que os fatores de competitividade de uma nação refletem diretamente em suas empresas. Ou seja, corporações de um ambiente que possua uma economia vigorosa tendem a ter maior capacidade de concorrer

\section{O FORTALECIMENTO DA}

\section{INTERNACIONALIZAÇÃO DE ORGANIZAÇÕES BASEADAS NO CONHECIMENTO É UM EXEMPLO IMPORTANTE DO AUMENTO DA COMPETITIVIDADE BRASILEIRA EM SETORES NOS QUAIS O PAÍS NÃO SE DESTACAVA}

no exterior. A correlação não é perfeita porque alguns setores produtivos têm melhor desempenho do que outros. Por isso as trocas internacionais podem trazer ganhos para todos os participantes.

Ao mesmo tempo em que as organizações brasileiras são influenciadas por aspectos relacionados à economia nacional, a capacidade delas competirem internacionalmente também é reflexo de suas decisões. Isso explica por que em um mesmo setor podem ser encontradas empresas com muita representatividade no cenário global e outras não.

Há uma controvérsia entre os estudiosos do desenvolvimento econômico sobre o grau de envolvimento que os governos devem ter na construção e no gerenciamento da competitividade dos países. As opiniões vão desde sua mínima intervenção até a que exerça um papel abrangente nessa questão. No primeiro caso, recomenda-se que ele adote medidas como: criar fatores de produção avançados (recursos humanos qualificados, conhecimento científico básico, informação econômica e infraestrutura), estimular a concorrência local, moldar prioridades nacionais e influenciar a sofisticação da demanda. No segundo, com uma intervenção mais ampla, inclui subsídios a setores não competitivos, proteção do mercado doméstico e, em alguns casos, até a produção pelo próprio governo. Um exemplo que pode suscitar polêmica é o caso da JBS, empresa brasileira com maior grau de internacionalização - segundo o índice da United Nations Conference on Trade and Development (UNCTAD) -, a maior produtora de proteína animal do mundo, com subsidiárias em 17 países. A corporação se aproveita das vantagens competitivas do país nesse segmento, como a ampla disponibilidade de terras e outros recursos naturais, mas também usufrui de benefícios proporcionados pelo governo brasileiro, na forma de empréstimos a juros subsidiados e participação no capital da empresa. Até agora, o crescimento da JBS tem sido impressionante, mas sua lucratividade tem desapontado. 


\section{PESQUISA E DESENVOLVIMENTO FAZEM TODA A DIFERENÇA}

Também há indicadores que ajudam a explicar como o comportamento das empresas influencia na sua capacidade de disputar o mercado internacional. Para isso, um dos fatores analisados é o seu investimento em pesquisa e desenvolvimento (P\&D). Segundo o ranking elaborado pela consultoria Booz \& Company em 2013, apenas 6 corporações brasileiras figuram entre as mil companhias de capital aberto no mundo que mais investem em P\&D. São elas: Vale, Petrobras, Gerdau, Totvs, CPFL e Embraer.

De 2011 para 2012, enquanto o investimento global em P\&D cresceu 5,8\%, o das companhias brasileiras recuou $18 \%$, chegando a US\$ 3 bilhões. No mesmo período, o investimento das empresas chinesas aumentou $38 \%$, atingindo a marca de US\$ 20 bilhões. Apesar disso, as corporações norte-americanas e japonesas ainda respondem por $90 \%$ do investimento em P\&D no mundo.

No relatório do FEM, a capacidade de inovação das empresas brasileiras figura em $36^{\circ}$ lugar, atrás de países como Estônia e Porto Rico. Além do baixo investimento em P\&D, parte da dificuldade em inovar pode estar relacionada a questões estruturais como a baixa disponibilidade de engenheiros e cientistas no país (o Brasil aparece na $112^{\mathrm{a}}$ posição), escassez de tecnologias avançadas (63 ${ }^{a}$ ) e pelo fato do governo não incentivar as instituições inovadoras na compra de produtos e serviços $\left(69^{\mathrm{a}}\right)$. Além disso, o baixo nível educacional $\left(121^{\mathrm{a}} \mathrm{em}\right.$ termos de qualidade da educação e $85^{\mathrm{a}}$ no acesso ao ensino superior) não contribui para a melhora desse quadro.

\section{ELES SE DESTACAM: SETORES POTENCIAIS}

O relatório aponta ainda que a vantagem das empresas brasileiras em mercados internacionais está mais ligada a recursos naturais e custos de mão de obra do que desenvolvimento de produtos e processos únicos. Exemplos dessas companhias são: Vale (minérios), Suzano (papel e celulose), JBS (carne), BRF (frango), Marfrig (carne), Votorantim (metais, suco de laranja, papel e celulose) e Petrobras (petróleo).

Além disso, corporações que correspondem a setores industriais - como as citadas acima e outras como Gerdau (aço), Metalfrio (refrigeradores), Marcopolo (ônibus), Tigre (tubos), Weg (motores) e Sabó (autopeças) - também têm destaque.

Entretanto, é possível observar novas áreas se sobressaírem no cenário global, como é o caso das empresas de serviço que têm como maior ativo o seu capital intelectual, como a Stefanini (serviços e soluções em tecnologia), a Totvs (software) e a Integration (consultoria empresarial). O fortalecimento da internacionalização de organizações

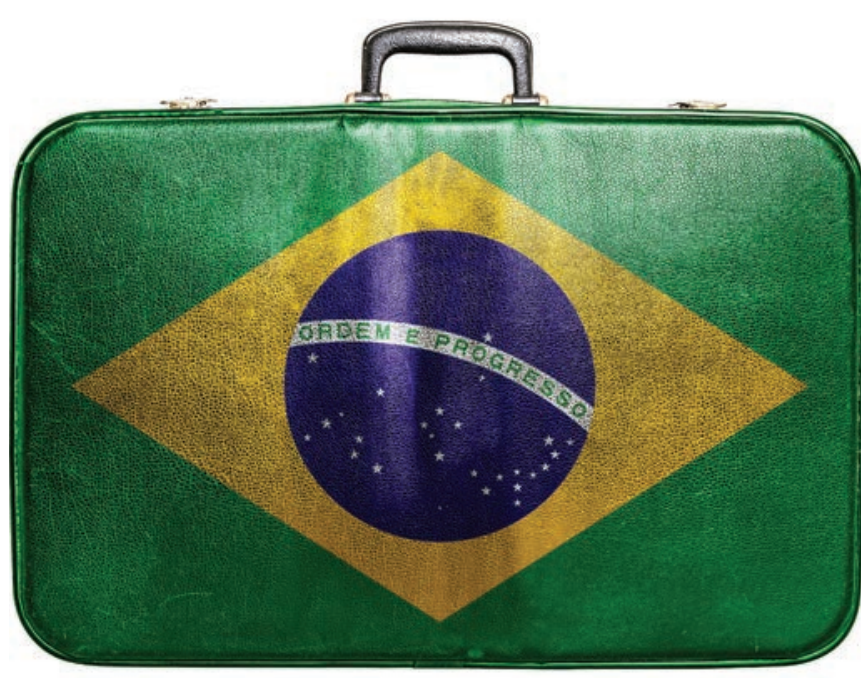

\section{Investimento das empresas em pesquisa e desenvolvimento}

\begin{tabular}{lcc} 
Empresa & Posição global & $\begin{array}{c}\text { Gasto em P\&D em } \\
\mathbf{2 0 1 2} \text { (US\$ bilhões) }\end{array}$ \\
Vale & 95 & 1,49 \\
Petrobras & 119 & 1,15 \\
Gerdau & 714 & 0,123 \\
Totvs & 902 & 0,09 \\
CPFL & 937 & 0,085 \\
Embraer & 985 & 0,078 \\
\hline
\end{tabular}

Fonte: Booz \& Company. 2013 Global Innovation 1000 Study.

nacionais baseadas no conhecimento é um exemplo importante do aumento da competitividade em setores nos quais o país historicamente não se destacava mundialmente.

Se por um lado o cenário econômico, social e institucional do Brasil ainda não favorece a sua competitividade internacional, a emersão de novas corporações mostra a capacidade do empresariado para contornar os desafios institucionais e conquistar seu espaço no contexto global.

A participação das multinacionais brasileiras nos mercados estrangeiros continua sendo tímida e ainda está longe de representar o país que tem a $7^{\mathrm{a}}$ maior economia do planeta. A melhora deste cenário deve passar pelo alinhamento entre a agenda social e econômica do governo e as estratégias das empresas nacionais.

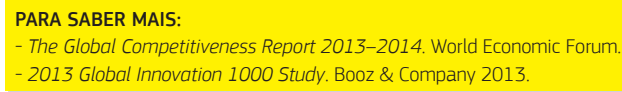

FÁBIO MARIOTTO > Professor da FGV-EAESP > fábio.mariotto@fgv.br PEDRO ZANNI > Professor da FGV-EAESP > pedro.zanni@fgv.br 